\title{
Response of the Bucket Foundation in Calcareous Sand under Horizontal Dynamic Load
}

\author{
Li Wang ${ }^{1, *}$, Xiaobing $\mathrm{Lu}^{1}$ and Zhongmin $\mathrm{Shi}^{2}$ \\ ${ }^{1}$ Institute of Mechanics, Chinese Academy Sciences, Beijing, 100190, China \\ ${ }^{2}$ Research Center, CNOOC, Beijing, 100027, China
}

\begin{abstract}
Experiments to determine the horizontal static bearing capacity are carried out first. The static bearing capacity is a reference for choosing the amplitudes of dynamic load. Then a series of experiments under dynamic horizontal load are carried out in laboratory to study the influences of factors, such as the scales of bucket, the amplitude and frequency of load, the density of soils etc.. The responses of bucket foundations in calcareous sand under horizontal dynamic load are analyzed according to the experimental results. The displacements of bucket and sand layer are analyzed.
\end{abstract}

Keywords: Calcareous sand, bucket foundation, horizontal dynamic load.

\section{INTRODUCTION}

A suction bucket foundation is a closed-top steel tube that is lowered to the seafloor, allowed to penetrate the bottom sediments under its own weight first, and then pushed to full depth with suction force produced by pumping water out of the interior. In recent years, suction bucket foundations have been frequently used for gravity platform jackets, jackups [1-3]. They also have the potential of being used for several other purposes, such as offshore wind turbines, submarine systems and seabed protection structures [4-7]. The first advantage of suction bucket foundations are attractive because of the convenient method of installation and repeatedly use. For an example, a suction bucket foundation with a diameter of $9 \mathrm{~m}$ and a height of $10 \mathrm{~m}$ can be installed in 1 3 hours, by using only a pump. The second advantage is that it may mobilize a significant amount of passive suction during uplift under some conditions, although the mobilisation of suction depends mainly on the load rate and recommendations are actually to not rely on the suction for design [4]. Despite some studies about the installation and bearing capacity have been studied, the detail responses of the suction bucket foundations under dynamic loads have remained unknown [8-10]. The dynamic load condition is significant when suction buckets are used as the foundation of an offshore structure. Wave load, ice-induced or wind- induced load causes the foundation to be subjected to cyclic loads [11-14]. The lack of experience with these load conditions leads to a proposal for a test program intended to gain a deeper understanding. The considerable expense and time consuming nature of prototype tests mean that the investigation of the bearing capacity of real scale devices is of limited practicality, while it is much easier to change parameters in small scale tests. The soil type may be varied in these cases. The dimensions of the suction bucket and other process parameters may be varied conveniently also.

*Address correspondence to this author at the Institute of Mechanics, Chinese Academy Sciences, Beijing, 100190, China; Tel: 13810091054; E-mail: zaowang2008124@163.com
In the tropic marine area, such as in the zone of South China Sea, the Australia Sea, the calcareous sand is distributed widely. This type of sand has special characteristics: crushing and disintegration at low stresses compared with siliceous particles, macropores and cementation [15].

Several studies on the static and dynamic responses of suction piles and suction caissons in calcareous sand have been undertaken in the last three decades. Angemeer [16] and Khorshid [17] carried out field pile tests in calcareous sand. Randolph et al. [18] studied the static and dynamic responses of suction piles in fine calcareous sand by centrifugal experiments. Dyson and Randolph [19], Riadh and Poulos $[20,21]$ et al. studied the horizontal static bearing capacity of piles in calcareous sand in north-west shelf of Australia. Watson and Randolph [22] carried out centrifugal experiments to study the vertical bearing capacity of suction caissons under drained and undrained conditions in the calcareous sand in north-west shelf of Australia. Cassidy et al. $[23,24]$ studied the bearing capacity of circular footings in calcareous sand by experiments and numerical modeling. Chu et al. [25] and Shan et al. [26] studied the static bearing capacity of plate anchors in calcareous sand.

Generally, the study on the dynamic responses of suction foundations in calcareous sand is very little. In this paper, aims are at the dynamic responses of bucket foundations in the calcareous sand distributed in the South China Sea. A series of experiments in laboratory are carried out to investigate the effects of factors, such as the amplitude and frequency of load, the density of sand, the scales of bucket, and also to investigate the characteristics of dynamic responses, such as the development of pore pressure and displacements.

\section{INTRODUCTION OF EXPERIMENTAL SETUP}

\section{Properties of Experimental Soils}

Loose calcareous sand obtained from Yongshu reef in the South China sea is used in experiments. The coarse grains whose diameters are bigger than $0.5 \mathrm{~cm}$ are griddled first 
before grain series analysis. The grain series curve is shown in Fig. (1). The physical parameters are shown in Table $\mathbf{1}$.

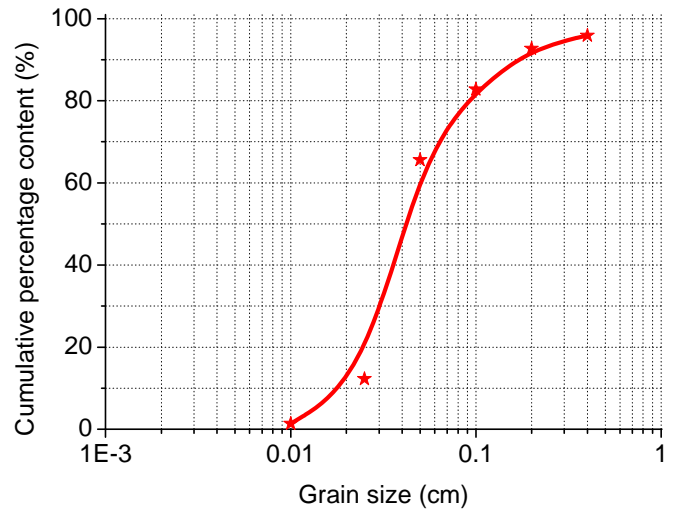

Fig. (1). Grain series curve.

Table 1. Physical Parameters of Calcareous Sand Used in Experiments

\begin{tabular}{|c|c|c|c|c|c|}
\hline Cohesion C & $\begin{array}{c}\text { Internal } \\
\text { Friction } \\
\text { Angle } \Phi\end{array}$ & $\begin{array}{c}\text { Permeability } \\
\mathbf{k}(\mathbf{c m} / \mathbf{s})\end{array}$ & $\mathbf{d 1 0}(\mathbf{c m})$ & $\mathbf{D 6 0}(\mathbf{c m})$ & $D_{r}$ \\
\hline \hline 0 & $47.7^{\circ}$ & $5 \times 10-2$ & 0.024 & 0.046 & $0.5 \sim 0.6$ \\
\hline
\end{tabular}

\section{Model Box}

The model box made by organic glasses with an inner scale of: $\rightarrow$ length $\times$ width $\times$ height $=50 \mathrm{~cm} \times 50 \mathrm{~cm} \times 45 \mathrm{~cm}$. The steel circular bucket is placed in the center of the model box.

\section{Electro-Hydraulic Service Load System}

The layout of load system is shown in Fig. (2). The load system may output force or displacement. The load amplitude of force ranges from 0 to $1000 \mathrm{~N}$ or displacement ranges from 0 to $5 \mathrm{~cm}$. The output frequency ranges from 0.1 to $20 \mathrm{~Hz}$. Displacement control mode is adopted in the experiments in this paper. The force transducers and pore pressure transducers (PPTs) are placed before the starting of experiments. The counter force of bucket, the displacement of bucket and soil and the pore pressure are measured during each experiment.

\section{The Transducers and Data Acquisition System}

Two force transducers are made by the 701 institute in China and the measure ranges are $150 N$ and $800 N$, respectively. The PDCR81 type PPTs are made by Druck Co. in England and have a diameter of $0.64 \mathrm{~cm}$ and a length of $1.14 \mathrm{~cm}$. The measure ranges are $35 \mathrm{kPa}, 7.5 \mathrm{kPa}$, respectively. All PPTs must be saturated in a vacuum environment and demarcated before each experiment. The data acquisition system (USB2005 16 bit) is made by ALTAI Co. of China, the sampling frequency is $10 \mathrm{kHz}$.

\section{Preparation of Sand Foundation and Experimental Steps}

\section{Sand Foundation Preparation}

The sand layer with a height of $27 \mathrm{~cm}$ and a dry density of $1.26 \mathrm{~g} / \mathrm{cm}^{3}$ is compacted by 9 layers. The model bucket is

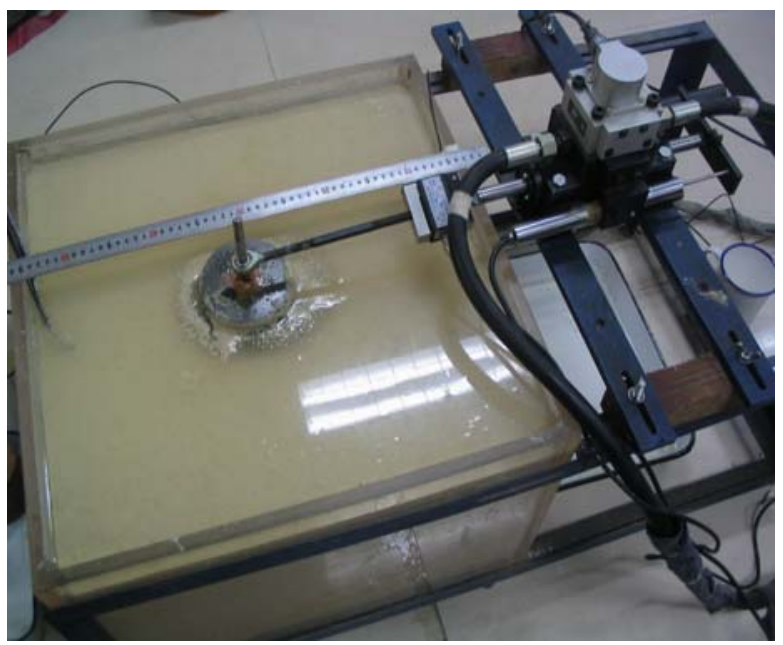

Fig. (2). Sketch of the experimental layout.

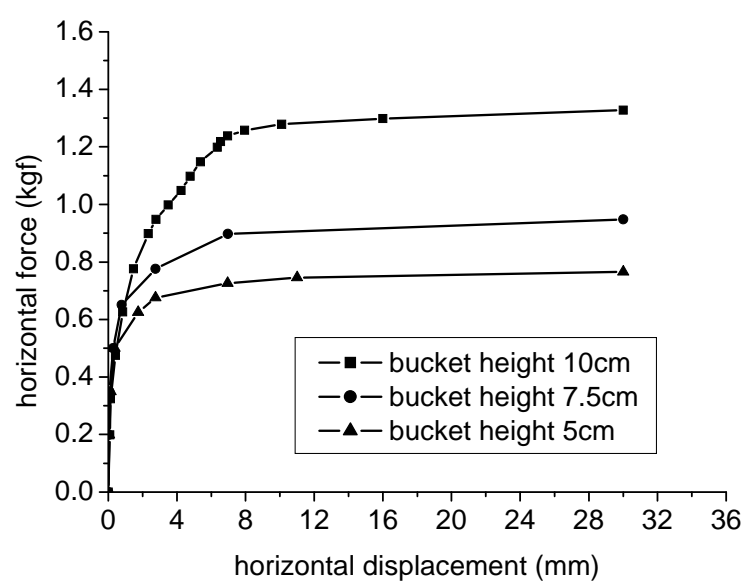

Fig. (3). Curves of horizontal static load-displacement.

pressed into the sand layer. The PPTs are placed in the sand layer unfixed. The top of the bucket is at the same level of the sand layer surface. Then, the sand layer is saturated by filling water from the bottom of the model box. In order to assure the percolation of water uniform and prevent piping, a layer of fine sand with a thickness of $1.0 \mathrm{~cm}$ is put on the bottom of the model box. There is a layer of geotextile over the layer of fine sand. Since the permeability of the calcareous sand is always big, the water head method (applying water pressure only) is adopted to saturate the sand layer. The saturation degree is over $98 \%$ by this method. The water surface is $2 \mathrm{~cm}$ above the sand surface after saturation. The saturated sand layer is lay for 24 hours before load is applied.

The positions of the PPTs change during experiments, thus the positions are measured after each experiment.

\section{Experimental Steps}

(a) Prepare sand foundation; check transducers.

(b) Connect the load head and the bucket by a gimbal which may move vertically.

(c) Measure the initial state of bucket and sand foundation (including the position of load head, water depth above 


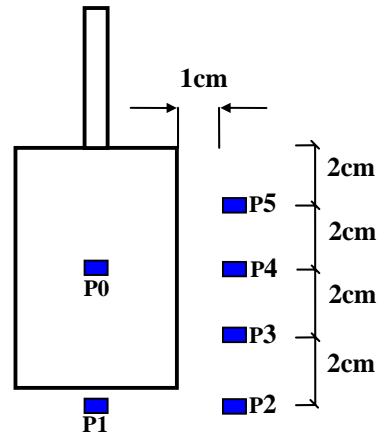

(a)

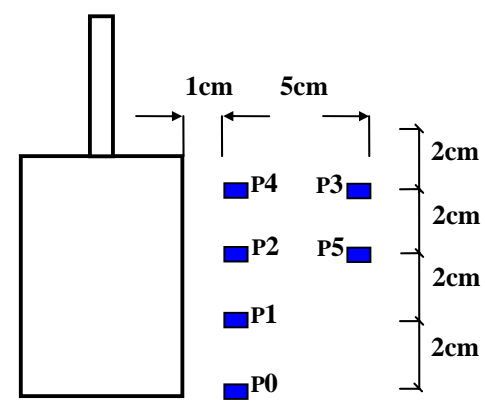

(b)

Fig. (4). Layout of pore pressure transducers.

the sand surface and positions of bucket and sand surface.). Turn on the load system, measure the counter force and vertical displacement of bucket, pore pressure.

(d) Stop experiments when the vertical displacement of bucket does not develop.

\section{EXPERIMENTS UNDER STATIC HORIZONTAL LOAD}

For understanding the primary characteristics of bucket under static horizontal load and provide a reference for choosing the dynamic load amplitude, the static horizontal experiments for different length-diameter-ratio of bucket are carried out. Force control mode is adopted in static experiments. The increment in each step is changed. It is $10 \mathrm{~N}$ each step at the beginning and $1 \sim 5 \mathrm{~N}$ at the later stages. After each increment of load, the data are recorded when the displacement is stable. The experiment is stopped when the displacement of bucket is over $1 \mathrm{~cm}$ or the entire model bucket is instable.

Three steel model buckets used in experiments have the same inner diameter of $10 \mathrm{~cm}$, the inner heights of them are $10 \mathrm{~cm}, 7.5 \mathrm{~cm}$ and $5 \mathrm{~cm}$ respectively. The top cup is with a height of $1.0 \mathrm{~cm}$. The bucket's wall is with a thickness of 0.2 $\mathrm{cm}$.

Fig. (3) shows the curves of horizontal forces versus horizontal displacements under different length-to-diameter ratios of buckets. It is shown that the bearing capacities are $1.3 \mathrm{~kg}, 1.0 \mathrm{~kg}$ and $0.7 \mathrm{~kg}$ respectively when the corresponding displacements are $0.6 \mathrm{~cm}, 4 \mathrm{~cm}$ and $4.0 \mathrm{~cm}$ for each and the bucket heights are $10 \mathrm{~cm}, 7.5 \mathrm{~cm}$ and $5 \mathrm{~cm}$, respectively.

\section{EXPERIMENTS OF BUCKET FOUNDATIONS UN- DER HORIZONTAL DYNAMIC LOAD}

In experiments, we focus on the displacements of bucket, deformation of sand layer, the counter force of bucket and the pore pressure. To obtain the distribution characteristics of pore pressure in horizontal and vertical directions, the layout of PPTs is shown in Fig. (4).

\section{Repeatability of Experiments}

For reliability, we repeated the experiment. Fig. (5) shows the displacements of bucket and soil layer in three repeated experiments. It is shown that the three results are agreement each other well.

Development of the deformation, counter force and pore pressure.

The experiments are carried out under the conditions of load amplitude $0.3 \mathrm{~cm}$, load frequency $0.15 \mathrm{~Hz}$ and the bucket's height $\times$ diameter $=10.0 \mathrm{~cm} \times 10.0 \mathrm{~cm}$.

\section{Development of the Settlement of Sand}

Fig. (6) shows the position of sand surface after experiments. In Fig. (6), Lines 1 and 2 denote the settlements of each point on the surface of sand layer before and after experiments. It is shown that the sand settles obviously in a range of one time that of the bucket's diameter from the center of bucket. The settlement of sand decreases with the distance from the bucket's side wall. Many coarse sand settles near the bottom in which zone having the biggest settlement.

During loading, it can be seen obviously that the sand around the bucket settles while the bucket rises gradually. There is a gap between the bucket's wall and the surrounding sand. The sand grains slide towards the gap and forms a slope. The coarse grains slide to the bottom of the gap. The reason is that under horizontal dynamic load, the sand surrounding the bucket is disturbed. The disturbance decreases with distance caused by the damping. Therefore, the nearer to the bucket, the larger deformation it would be. Because the calcareous sand grains is coarse and angular and has big permeability, the pore pressure increases little and the grains are not easy to flow, at the same time, the sand may be dilatant, so the bucket rises when the weight is light.

\section{Development of the Bucket's Displacement}

Fig. (7) shows the curves of bucket's vertical displacement changing with time. It is seen that the bucket rises with time, and the rising velocity gradually decreases. The reason is that the load causes the damage of the sand structure at the first stage and the sand grains slide towards to the bottom of the gap between the bucket and sand foundations. At the same time, the sand may be dilatant, which leads the bucket rises and the bearing capacity of the bucket decreeses. At last stage, load, bucket and sand foundation forms a new stable state. In the present conditions, the bucket rises about $2.0 \mathrm{~cm}$ (equal to $20 \%$ of the bucket's height).

\section{Development of the Counter Force}

Fig. (8) shows the curves of the counter force changing with time. It is shown that at the first stage, the counter force of bucket is the biggest, and then decreases gradually to a stable value. The counter force decreases about $50 \%$ at last 


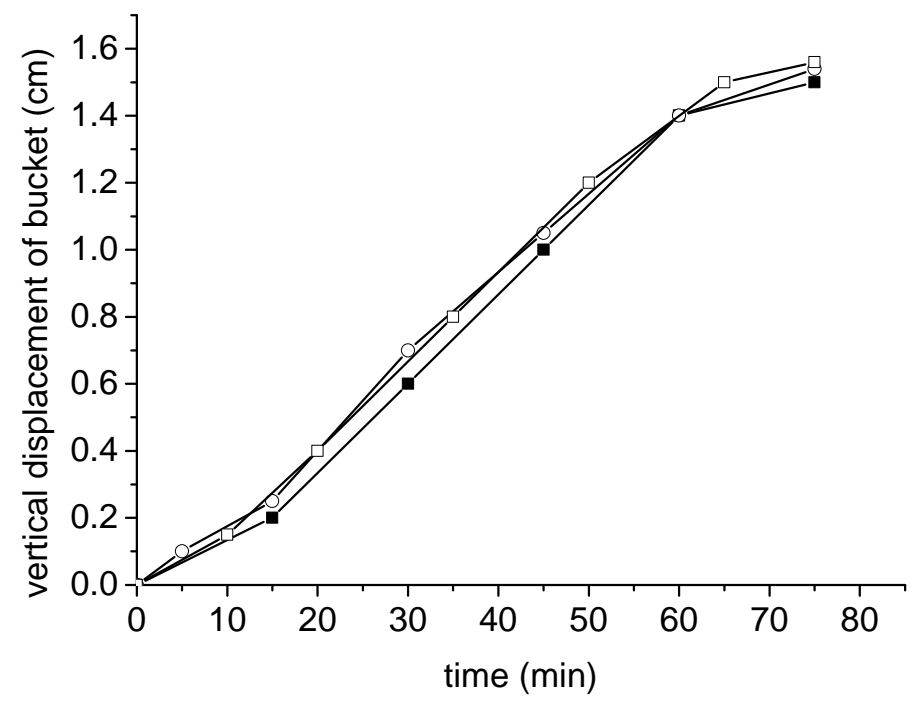

(a) Displacement of the top of bucket (The three lines denotes the results in three experiments under the same conditions)

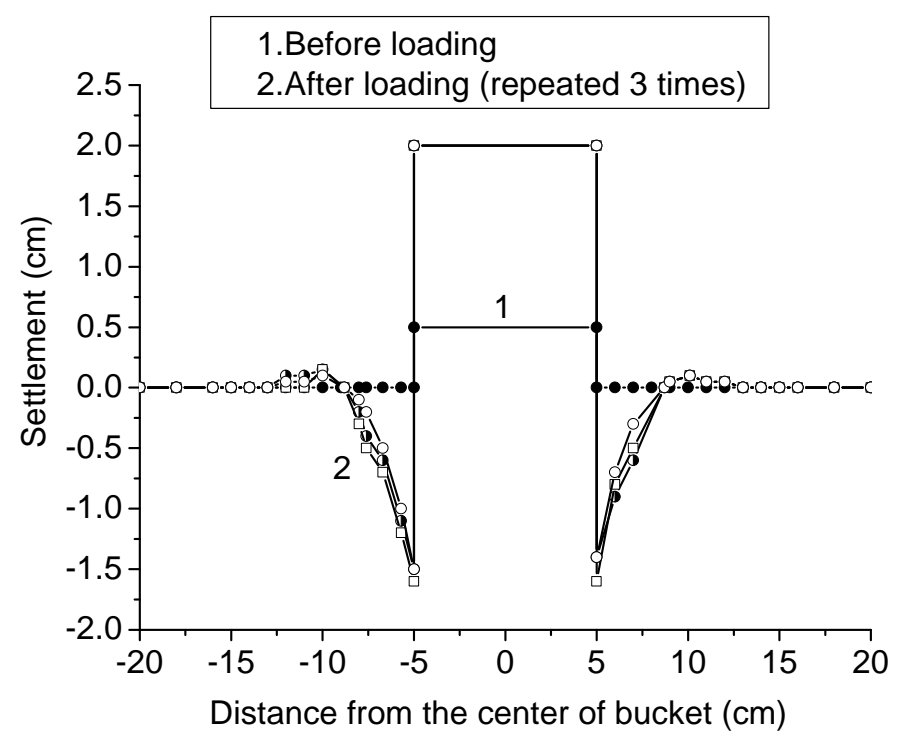

(b) Settlement

Fig. (5). Repeated experiments (The line 1 denotes the surface position of sand and bucket before experiments. Line 2 denotes the surface position of sand and bucket after experiments under the same conditions).

at the conditions of load amplitude $0.3 \mathrm{~cm}$ and load frequency $0.15 \mathrm{~Hz}$

The horizontal counter force of bucket is related mainly with the gravity of the bucket and the soil inside the bucket, the friction force between the bucket wall and the sand, the sand pressure around the bucket, the horizontal friction force, the vertical counter force at the bottom of the bucket and the position of load head. With the formation of settlement zone and the rise of the bucket, the contact area between the bucket side wall and the sand decreases, which leads to the decrease of the friction between the side wall and the sand and the decrease of the sand pressure. Nevertheless, with the dissipation of the pore pressure gradually, the density of sand layer increases as well as the strength, then the bucket stop to rise. At last, the counter force of the bucket comes to a stable value.

\section{Development of the Pore Pressure}

Fig. (9) shows the development of pore pressure when the calcareous sand is covered by a $3.0 \mathrm{~cm}$ clay layer. Fig. (9a) shows the development of excess pore pressure. Figs. 9(b-g) shows the development of average excess pore pres- 


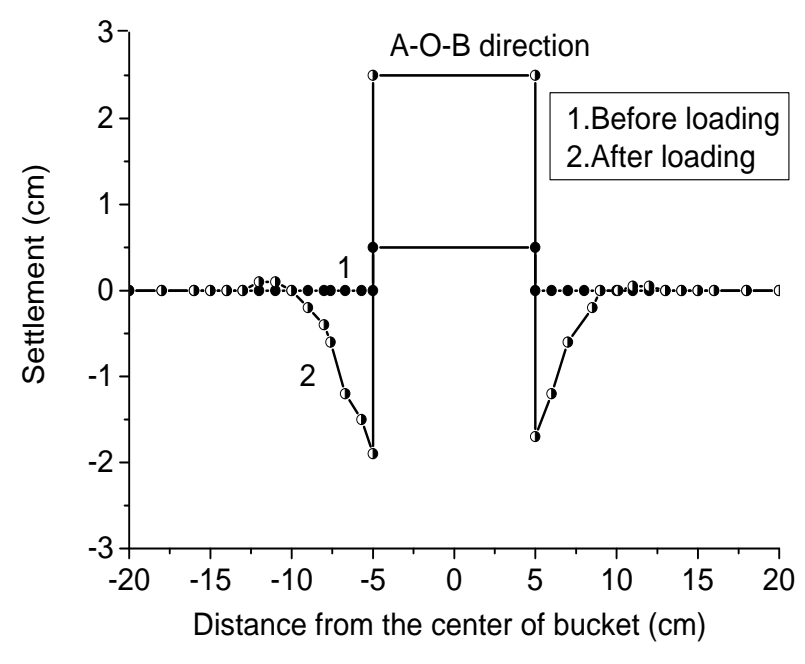

(a) In the direction of load

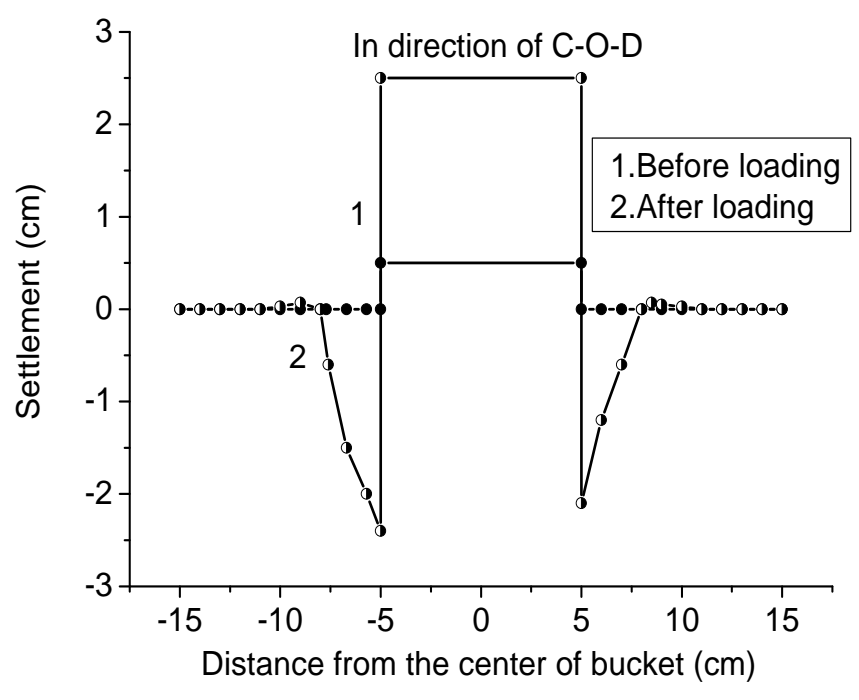

(b) Vertical to the direction of load

Fig. (6). Positions of bucket and soils.

sure (the cumulated pore pressure). It is shown that there exists accumulation of pore pressure. The pore pressure increases fast at the first stage and then increases slowly. The pore pressure develops to a stable value at last. In horizontal direction (P1, P5, P6), the biggest excess pore pressure occurs near the bucket side wall. In vertical direction $(\mathrm{P} 1, \mathrm{P} 4$, P3, P2), the excess pore pressure decreases with the depth. The reason is that the load head is located at the top of the bucket, so the upper part bears bigger disturbances than the lower part. The disturbance decreases in the horizontal direction from the bucket side wall. The excess pore pressure is thus bigger at the upper part and near the bucket side wall.

In this experiment, the load is lasted for 3600s. It can be seen that the pore pressure decreases after load stopped. The upper the position is, the faster the pore pressure decreases.

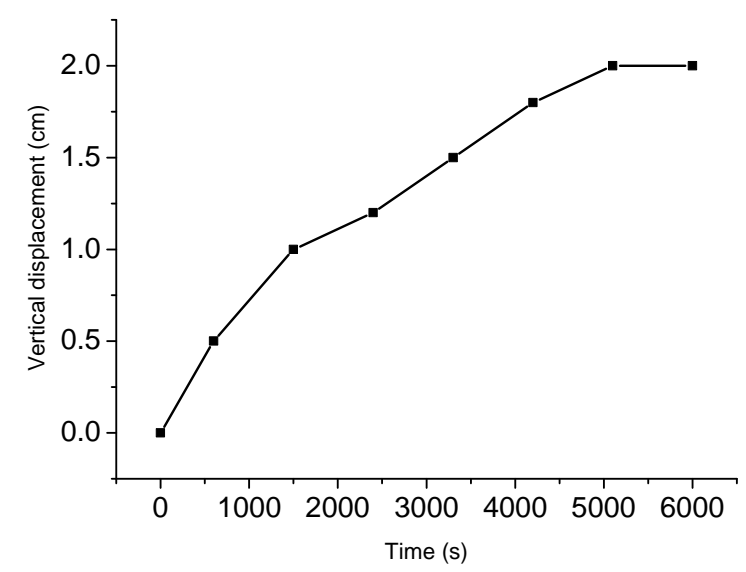

Fig. (7). The vertical displacement of bucket.

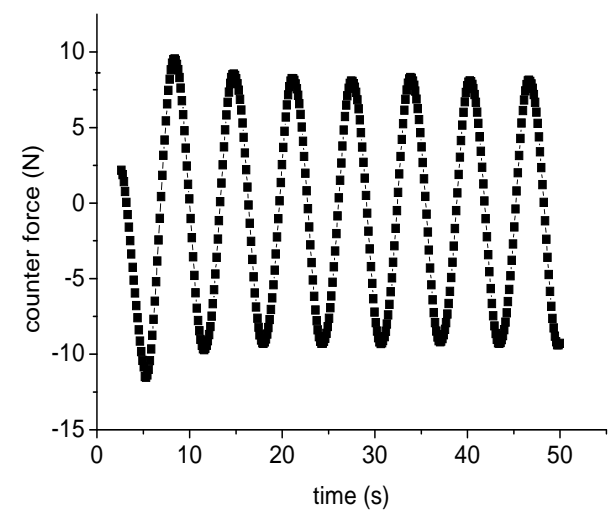

(a) Initial state

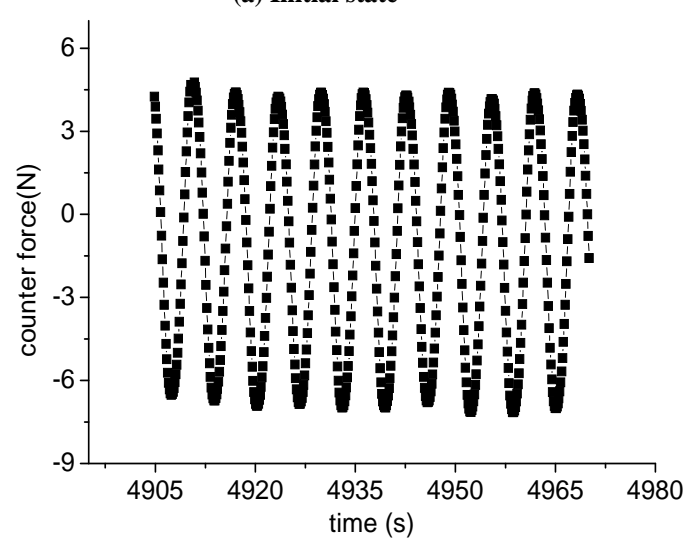

(b) After $4800 \mathrm{~s}$

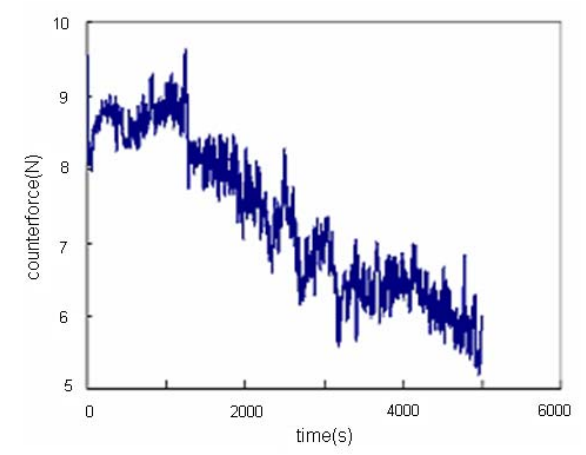

(c) Counter force envelop

Fig. (8). The curves of counterforce of soils with time. 


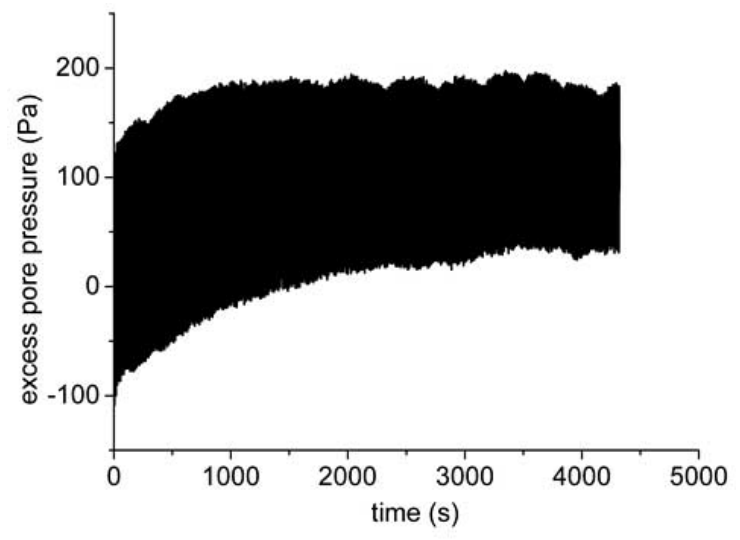

(a) Pore pressure versus time of P1

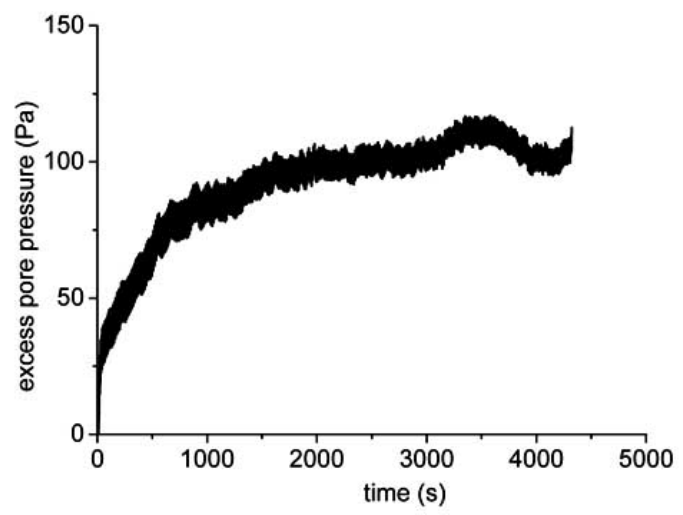

(b) P1

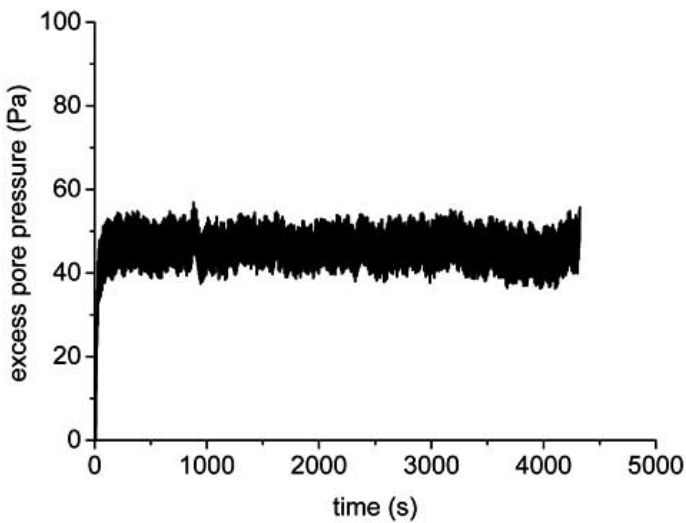

(c) P2

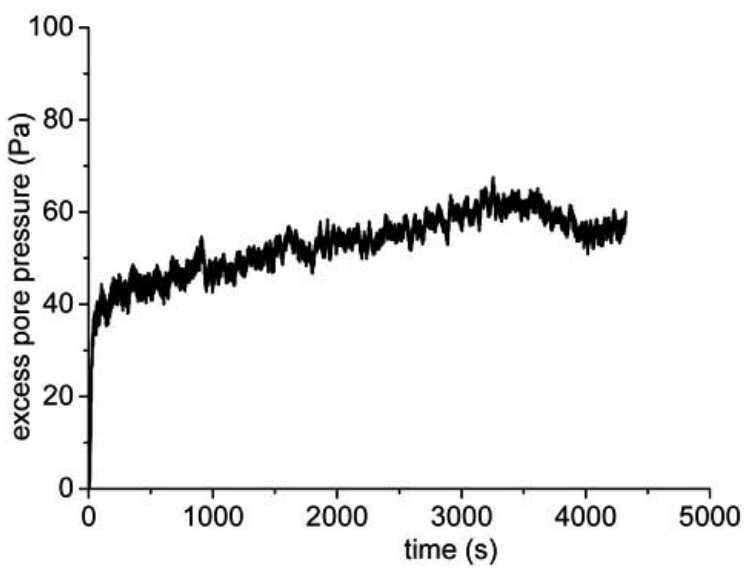

(d) P3

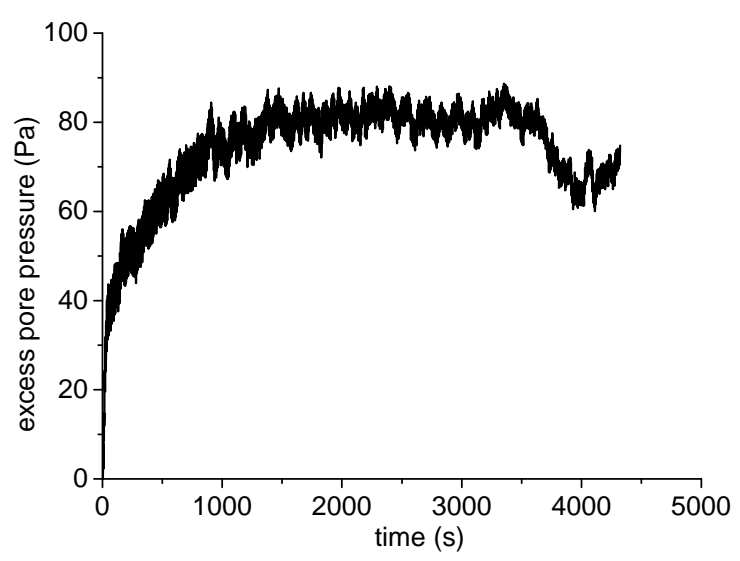

(e) P4

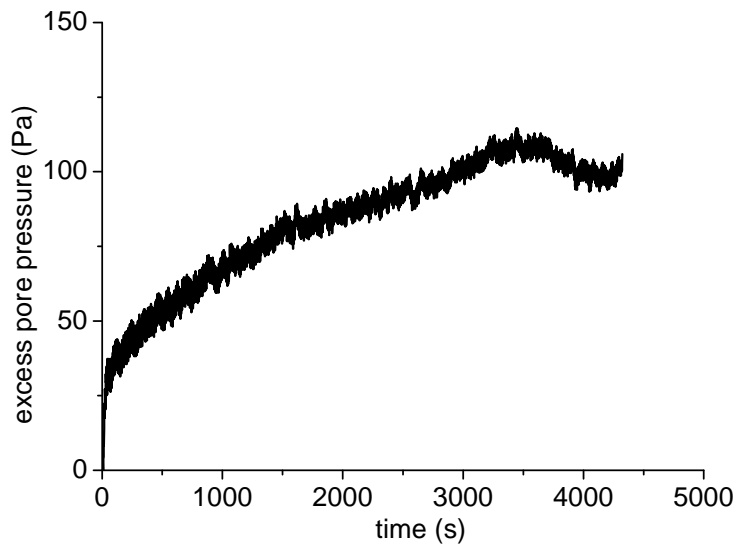

(f) P5

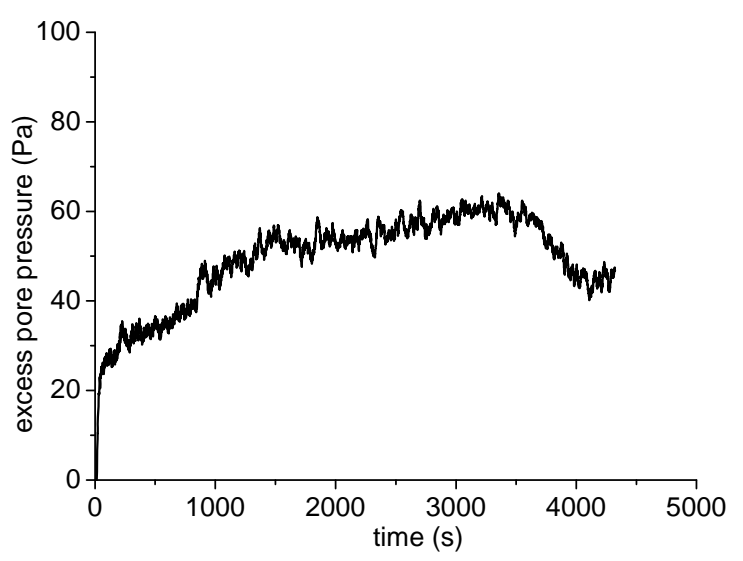

(g) P6

Fig. (9). Pore pressure versus time.

\section{The Changes of Density of Sand Layer}

There exists an obvious settlement zone after the experiments. The slope angle of this zone is about $20^{\circ}$. The density are measured after each experiment. It is shown that the density of sand near the bucket increases (Fig. 10). The sand surrounding the bucket is disturbed repeatedly and leads to 
the accumulation of plastic deformation, in other hand, with the dissipation of the excess pore pressure, the sand surrounding the bucket is densified. The density inside the bucket does not increase, for the upwards movement of the bucket.
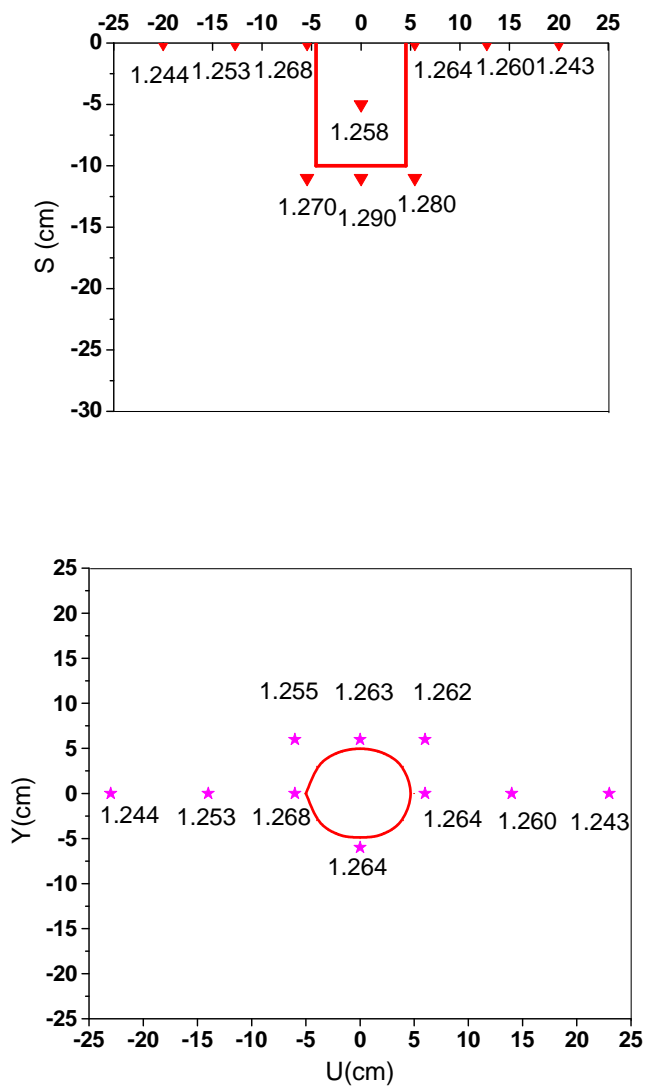

Fig. (10). Density distribution of soils after experiments (conditions: amplitude is and frequency is).

\section{Effects of Main Factors}

\section{Effects of Grain Scales}

In the experiments above, it seems that the bucket rises in the calcareous sand foundation. We think the reason is that the angularity of calcareous sand, coarse grains and the big permeability, so the sand layer dilates and the excess pore pressure is not easy to form. To validate it, the other two types of experiments are carried out. In the first type, the sand foundation is made by the calcareous sand whose grain diameter is less than $0.05 \mathrm{~cm}$ (Noted as Type A). In the second type, the sand foundation is made by the Mongolia sand whose grain diameter is the same as that in the first type but the grains are much more smooth. (noted as Type B). The experiments carried out in the fore-sections are named Type C. The initial densities are all the same in the three experiments.

It is shown that in experiments of Type A and C (Fig. 11), the bucket rises. The rise velocity and the final displacement in Type A is less than that in Type C. In Type B, under the condition of the frequency $0.1 \mathrm{hz}$ and the amplitude of $0.05 \mathrm{~cm}$, the bucket moves upwards, while the frequency increases to $1 \mathrm{~Hz}$, the bucket moves downwards.
As we all know, the calcareous sand is angular and has bigger friction angle than the Mongolia sand, so it is more difficult to deform. At the condition of low amplitude and frequency, the excess pore pressure is low and the degradation of strength is small because the permeability of the calcareous sand is big. Thus the calcareous sand and Mongolia sand slide towards the bottom of the bucket, which leads to the rise of the bucket. Another reason is dilatation of the calcareous sand. With the increase of load amplitude and frequency, Big excess pore pressure can accumulate in Mongolia sand, the bucket settles with the sand layer softening.

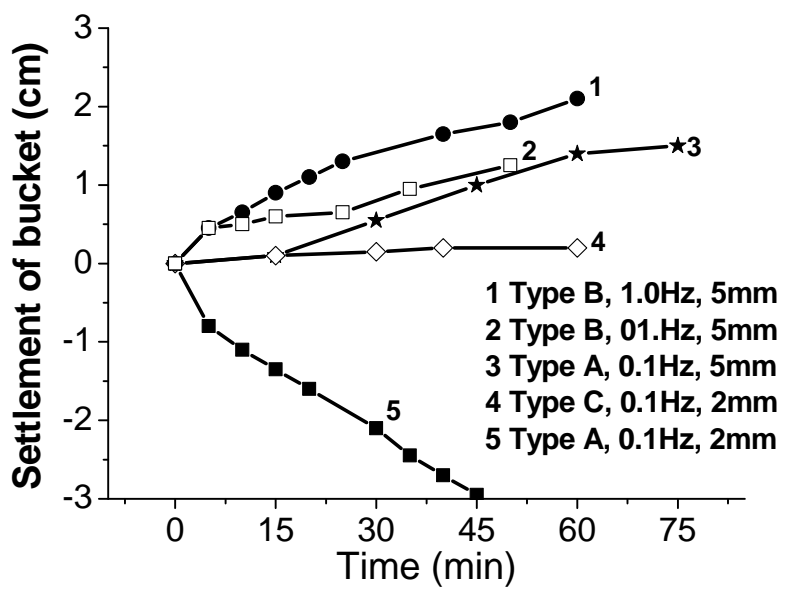

Fig. (11). The vertical displacements of buckets with time in different soil layers.

\section{Effects of Weight}

The results of the effects of weight on the dynamic responses of bucket and sand layer are shown in Fig. (12). It is shown from Fig. (12a) that the bucket's maximum settlement is from $0.3 \mathrm{~cm}$ to $0.5 \mathrm{~cm}$ when the weight is from $10 \mathrm{~N}$ to $20 \mathrm{~N}$. It can be seen from Fig. (12b) that the counter force of the bucket increases with the increase of weight. However, the deformation of the sand layer around the bucket is almost the same under different weights (12c). The contacted area between the bucket's outside wall and the sand layer decreases about 10\%, $20 \%$ and $30 \%$, and the counter force decreases $15 \%, 25 \%$ and $50 \%$ when the weights are $20 \mathrm{~N}$, $10 \mathrm{~N}$ and $0 \mathrm{~kg}$ respectively at last. The dry densities of the sand below and inside the bucket increase along with the rise of the weight. The reason is that the sand settles under the dynamic load, at the same time, the bucket settles also and presses the sand. When the weight is $20 \mathrm{~N}$, the dry density below the bucket is $1310 \mathrm{~kg} / \mathrm{m}^{3}$, when there is no weight, it is merely $1210 \mathrm{~kg} / \mathrm{m}^{3}$.

\section{Effects of Load Frequency}

Fig. (13) shows the development of vertical displacements of bucket and the final positions of sand surface and the bucket under different load frequencies. The experimental conditions are as follows: the load amplitude $0.2 \mathrm{~cm}$, load frequencies $0.1 \mathrm{~Hz}, 0.2 \mathrm{~Hz}$ and $1 \mathrm{~Hz}$, the bucket's height 


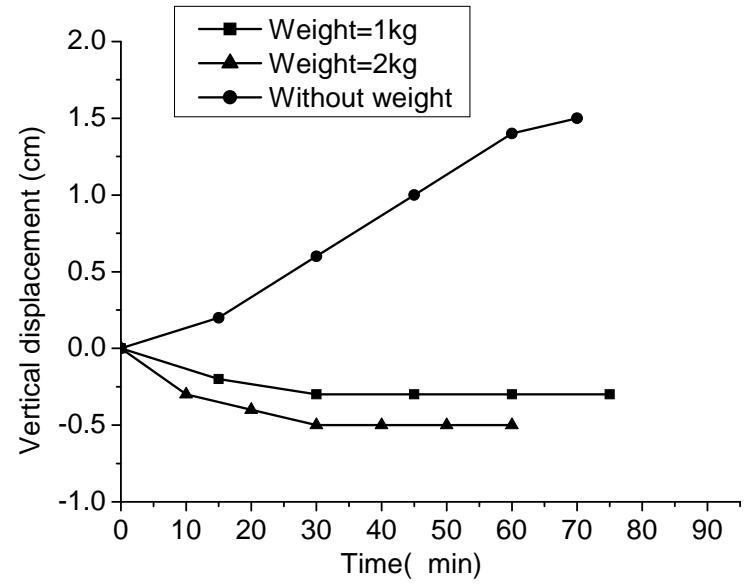

(a) Vertical displacement of bucket

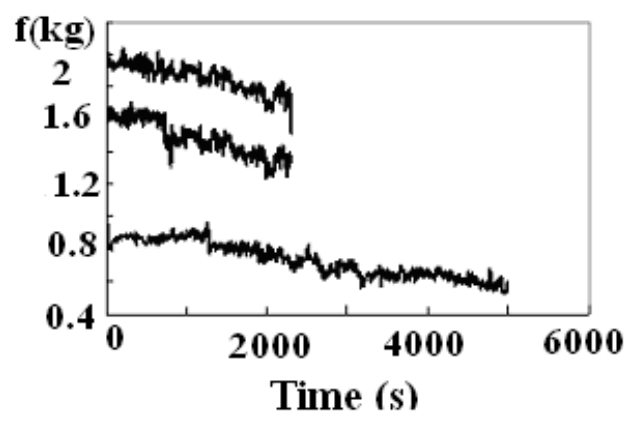

(b) Counter force of soil layer

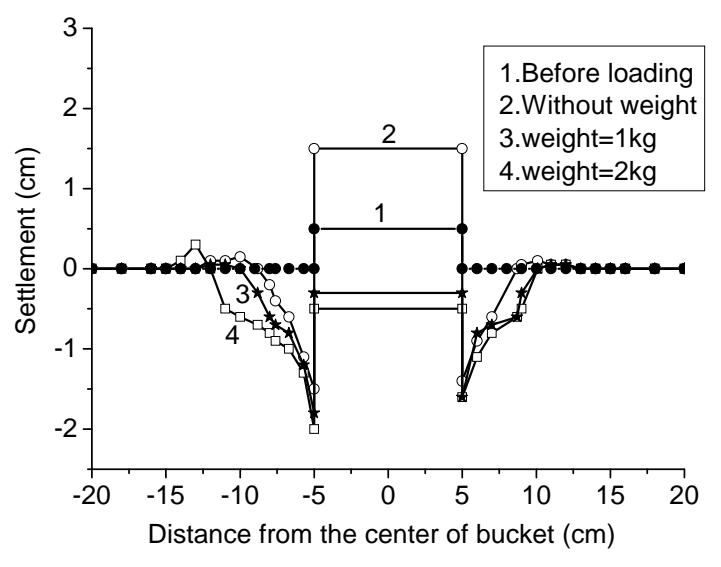

(c) Settlement

Fig. (12). Comparison of the results under different weights.

$10 \mathrm{~cm}$, the bucket's diameter $10 \mathrm{~cm}$. It is shown from Fig. (13a) that the bucket rises from $1.3 \mathrm{~cm}$ to over $4.0 \mathrm{~cm}$ while the load frequency increases from $0.1 \mathrm{~Hz}$ to $1 \mathrm{~Hz}$. Fig. (13b) shows the effects of the load frequency on the settlement of sand layer and the effected zone. It is shown that the maxi- mum settlement is $3.0 \mathrm{~cm}$ and the width of the gap reaches $5.0 \mathrm{~cm}$ when the load frequency is $1 \mathrm{~Hz}$.

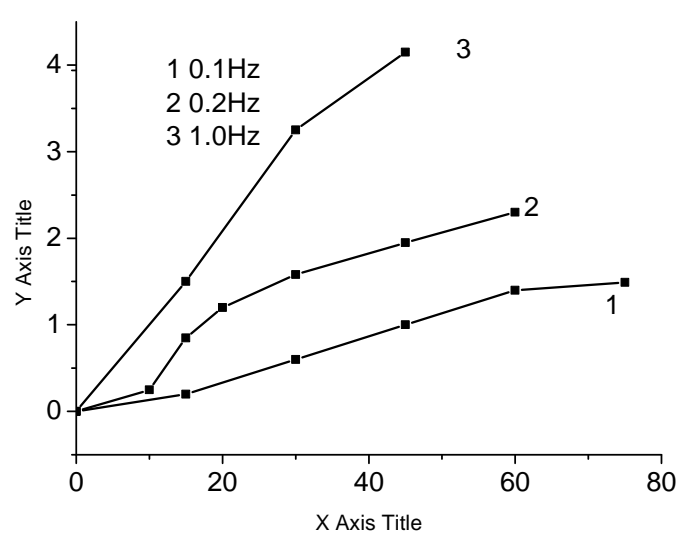

(a) Vertical displacement of bucket

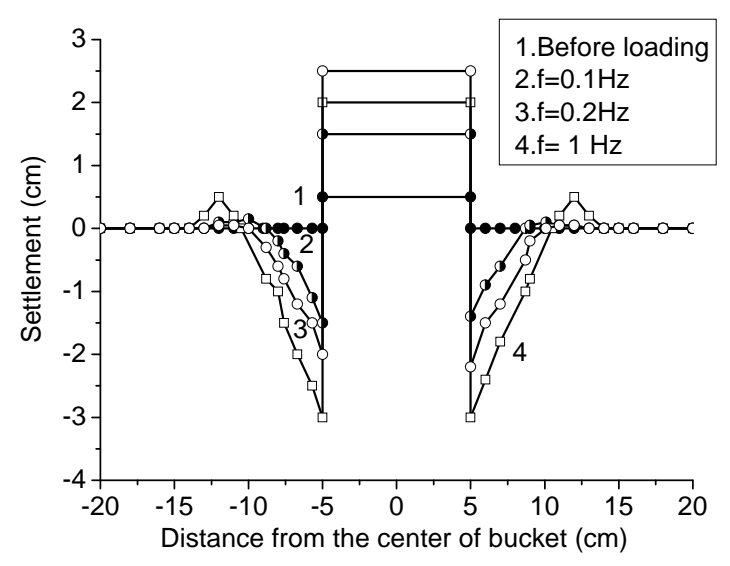

(b) Settlement

Fig. (13). Comparison of results under different frequencies.

\section{Effects of the Load Amplitude}

Fig. (14) shows the effects of the load amplitude on the settlements of the bucket and the sand layer. The load frequency is $0.1 \mathrm{~Hz}$, and the amplitude of applied displacement is $0.2 \mathrm{~cm}, 0.3 \mathrm{~cm}, 0.4 \mathrm{~cm}$, respectively. It is shown from Fig. (14a) that the bucket rises from $1.3 \mathrm{~cm}$ to $2.5 \mathrm{~cm}$ when the load amplitude increases from $0.2 \mathrm{~cm}$ to $0.4 \mathrm{~cm}$. It is shown from Fig. (14b) that the maximum settlement settlement is $3.2 \mathrm{~cm}$ and the maximum gap width is $5.0 \mathrm{~cm}$.

\section{Effects of the Bucket's Height}

Fig. (15) shows the final position of the bucket and the sand layer surface after dynamic load. It can be seen that the 


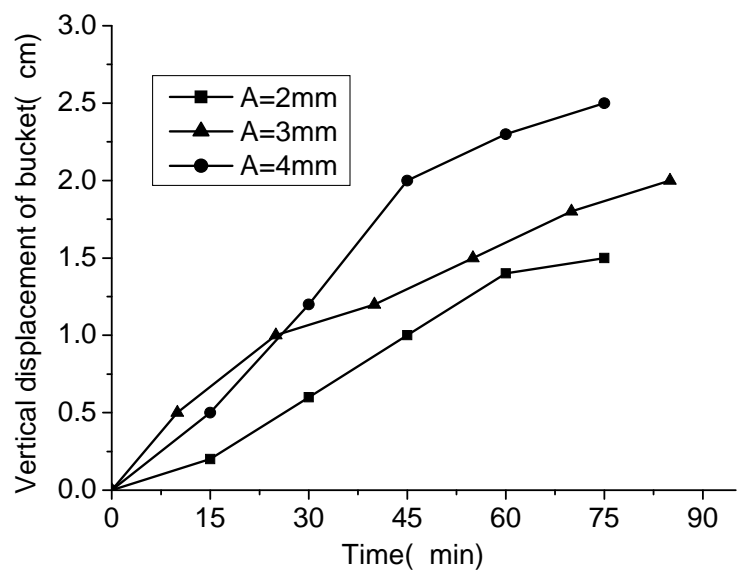

(a) Vertical displacement of bucket

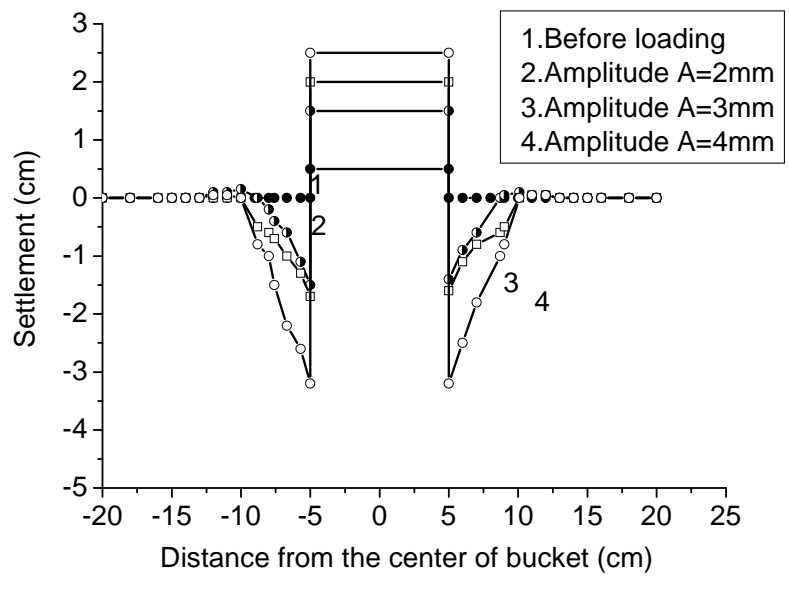

(b) Settlement

Fig. (14). Comparison of results under different load amplitudes.

bucket's displacement and the settlement of sand layer increase with the decrease of the bucket's height. The bucket's height affects not only the values of H/D (height-to-diameter ratio) but also $A_{h} / H$ (load amplitude-to-height). With the decrease of the bucket's height, the corresponding horizontal static bearing capacity decreases, the plastic deformation increases under the same load.

\section{Effects of the Initial Density of the Sand Layer}

Fig. (16) shows the results under two different initial densities. The two initial densities are $1260 \mathrm{~kg} / \mathrm{m}^{3}$ and $1200 \mathrm{~kg} / \mathrm{m}^{3}$, respectively. It is shown that the responses of the sand layer decreases with the increase of the initial sand's density. It is generally acknowledged that the increase of the initial density of the sand layer leads the increase of the strength and modulus, thus under the same load conditions, the deformation of the sand layer decreases.

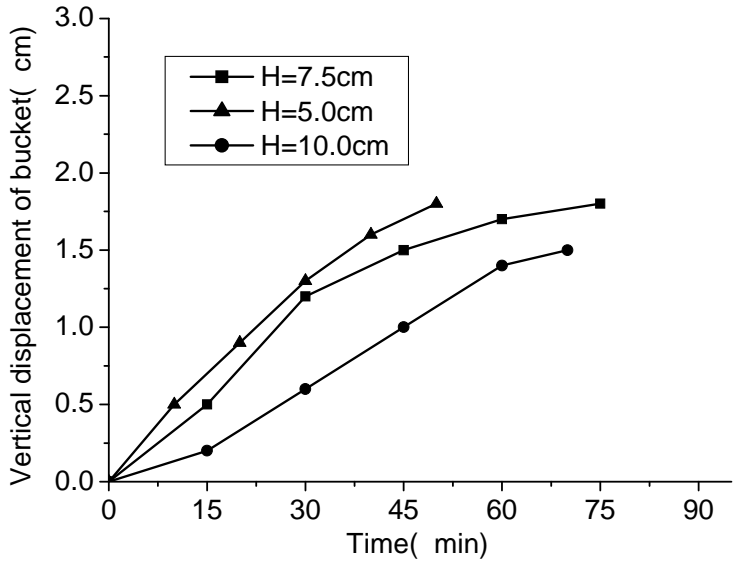

(a) Vertical displacement of bucket

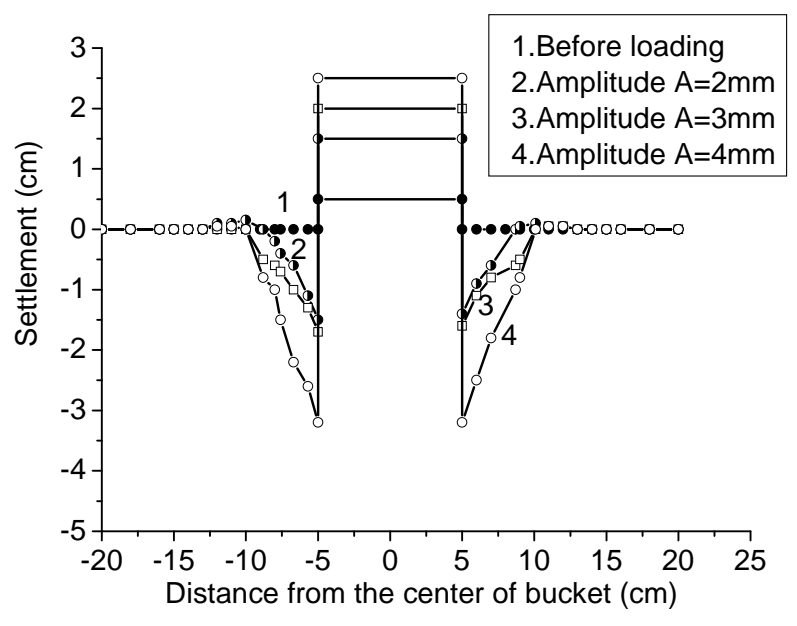

(b) Settlement

Fig. (15). Comparison of results under different bucket's heights.

\section{The Results Under Layered Soil Foundation}

The experiments of a $3 \mathrm{~cm}$ thick clay layer covering the calcareous sand layer are carried out. The bucket's top is at the same level as the surface of clay layer. It is shown that when there is a clay layer, there occur cyclic cracks on the surface during load. The soils around the bucket settle. The bucket rises only $0.2 \mathrm{~cm}$ after $60 \mathrm{~min}$ load with a frequency of $0.1 \mathrm{~Hz}$ and an amplitude of $0.2 \mathrm{~cm}$. When the frequency increases to $1.0 \mathrm{~Hz}$, the bucket rises $1.4 \mathrm{~cm}$ at last (Fig. 17a).

The dry density of the clay is $1650 \mathrm{~kg} / \mathrm{m}^{3}$ which is higher than that of calcareous sand. Thus the clay layer absorbs 


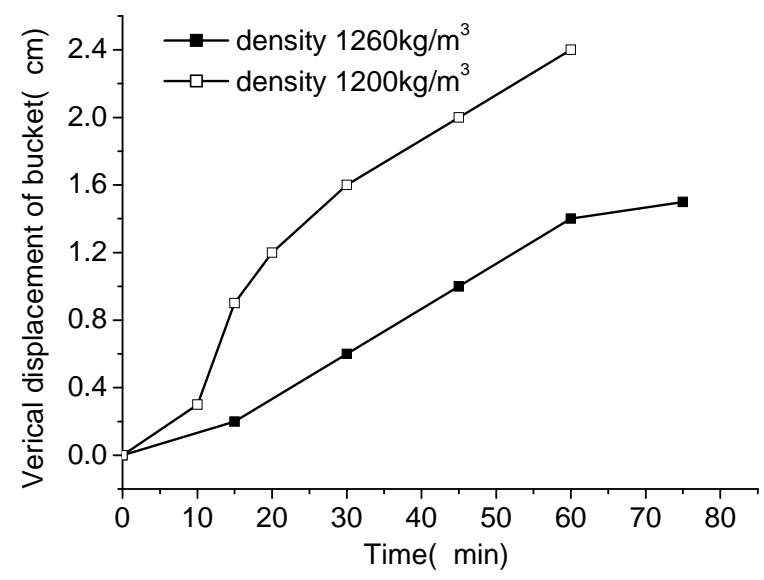

(a) Vertical displacement of bucket

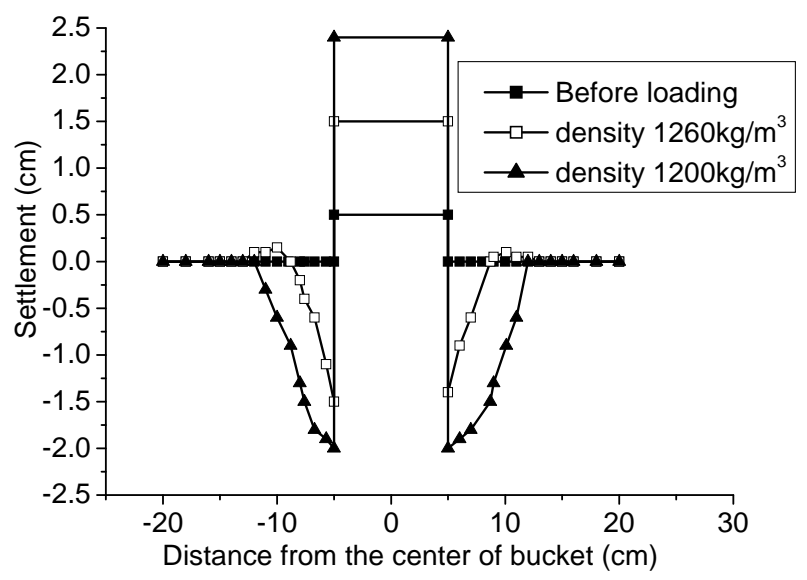

(b) Settlement

Fig. (16). Comparison of results under different soil densities.

much energy, at the same time, the distance of the load position to the calcareous sand increases. Thus the disturbance bear by the calcareous sand decreases (Fig. 17b) and the responses are accordingly decreeses.

\section{CONCLUSIONS}

1. The experiments under horizontal static load are carried out. The horizontal static bearing capacities under different bucket's heights are obtained.

2. The experiments under horizontal dynamic load are carried out. It is shown that under the dynamic load, the sand layer around the bucket forms a slope with an angle of $20^{\circ}$. The bucket rises when the weight is low. There occurs a crack between the bucket and the sand layer. The counter force of the bucket decreases obvious some time after the dynamic load acts for some time. The responses of the bucket and the sand layer come to a steady state gradually.

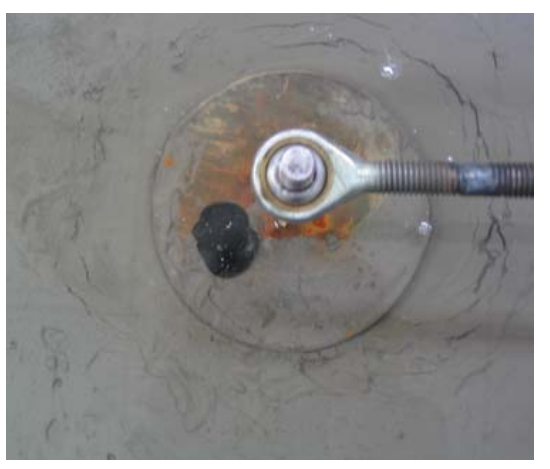

(a) Photos after experiments having over-layer

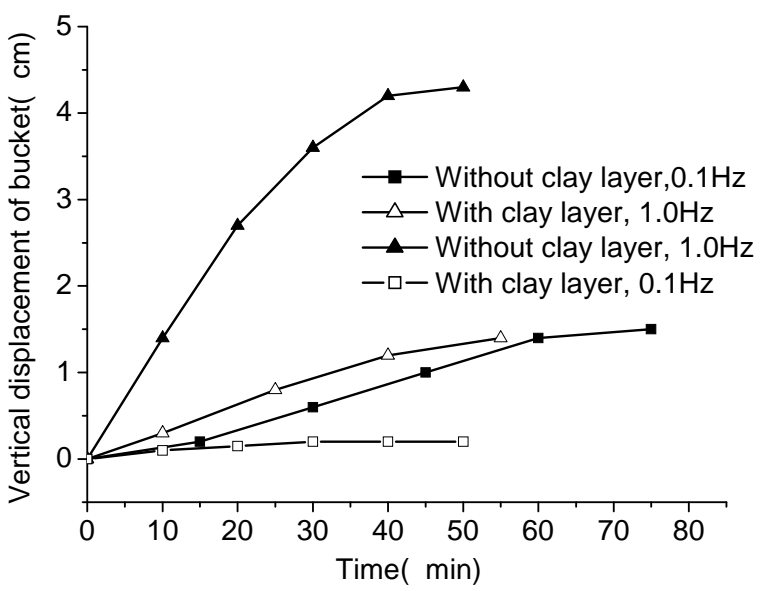

(b) Vertical displacement of the bucket versus time

Fig. (17). Experimental results of layered soils.

The responses of the bucket and the sand layer increase with the increase of the load frequency and amplitude. The weight increase leads the bucket moves downwards.

\section{ACKNOWLEDGEMENTS}

This work is supported by National High Technology Research and Development Program of China (863) and National Natural Science Fund (No. 10772182) and Key Program of Chinese Academy of Sciences"KJCX2-YW-L02". Zhao Jing and Wang Ailan take part in all the experiments.

\section{REFERENCES}

[1] E.C. Clukey, M.J. Morrison and J. Garnieret, "The response of suction caissons in normally consolidated clays to cyclic TLP loading conditions," In: Proc. Offshore Technol. Conf., Houston: OTC 7796, 1995, pp. 909-918.

[2] H.G.B. Allersma, F.J.A. Plenevaux and J.F.P.C.M.E. Wintgens, "Simulation of suction pile installation in sand in a geocentrifuge," In: Proc. $7^{\text {th }}$ Int. Offshore Polar Eng. Conf., vol.1, 1997, pp. 761765.

[3] H.G.B. Allersma, A.A. Kierstein and D. M. Aes, "Centrifuge modeling on suction piles under cyclic and long term vertical loading," 
In: Proc. $10^{\text {th }}$ Int. Offshore Polar Eng. Conf., Seattle, USA, International Society of Offshore and Polar Engineers, 2000, pp. 334-341.

[4] G.T. Housby and A.M. Puzrin, "A thermomechanical frame-work for constitutive models for rate-independent dissipative materials," Int. J. Plasticity, vol.16, No.9, pp. 1017-1047, 2000.

[5] B.W. Byrne, G.T. Housby, C.M. Martin and P.M. Fish, "Suction caisson foundations for offshore wind turbines," Wind Eng., vol. 26, No.3, pp. 145-155, 2002.

[6] B.W. Byrne and G.T. Houlsby, "Experimental investigations of the responses of suction caissons to transient combined loading," ASCE J. Geotech. Geoenviron. Eng., vol. 130, No. 3, pp. 240-253, 2004.

[7] K.H. Andersen and H.P. Jostad, "Foundation design of skirted foundations and anchors in clay," In: Proc. Offshore Technol. Conf., Houston, Texas, OTC 10824, 1999, pp. 1-10.

[8] D. Senpere and G.A. Auvergne, "Suction anchor piles-a proven alternative to driving or drilling," In: Proc. Offshore Technol. Conf., Houston, OTC4206, 1982, pp. 483-493.

[9] P.M. Aas and K.H. Andersen, "Skirted foundation for offshore structure," In: Proc. 9th Offshore South East Asia Conf., Singapore, World Trade Center, 1992, pp. 1-7.

[10] W. Dyme and G.T. Houlsby, "Drained behavior of suction caisson on very dense sand," In: Proc. Offshore Technol. Conf., Houston, OTC10994, 1998, pp. 765-782.

[11] T.L. Tjelta, J. Hermstad and E. Andenaes, "The skirt piled gullfaks c platform installation," In: Proc. Offshore Technol. Conf., Houston, OTC6473, 1990, pp. 453-462.

[12] A. Bye, C. Erbrich, B. Rognlien and T.I. Tjelta, "Geotechnical design of bucket foundation," In: Proc. Offshore Technol. Conf., Houston, OTC7793, 1995, pp. 869-883.

[13] X.B. Lu, Y.R. Wu and B.T. Jiao, "Centrifugal experimental study of suction bucket foundations under dynamic loading," ACTA Mech. Sin., vol. 23, pp. 689-698, 2007.

[14] X. B. L, J. H. Zhang, S. Y. Wang, G.L. Sun and Z.M. Shi, "Experimental study of the pore pressure and deformation of suction bucket foundations under horizontal dynamic loading," Chinese Ocean Eng. vol. 19, No. 4, pp. 671-680, 2005.
[15] J.R.C. De Mello and C.D.S. Amaral, "Closed-ended pile piles: Testing and piling in calcareous sand," In: Proc. of $21^{\text {st }}$ Ann. Offsore Technol. Conf., Australia, Houston, 1989, pp. 341-352.

[16] J. Angemeer, E. Carlson and J.H. Klick, "Techniques and results of offshore pile load testing in calcareous sand," In: Proc. $5^{\text {th }}$ Ann. Offshore Technol. Conf., Houston, Texas, OTC1894, 1973, pp. 677-692.

[17] M.S. Khorshid, "Development of geotechnical experience on the North-West Shelf," Aust. Geomech., vol. 19, pp. 11-21,1990.

[18] M.F. Randolph, M.P. O'Neill, D.P. Stewart and C. Erbirch, "Performance of suction anchors in fine-grained calcareous soil," In: Proc. Offshore Technol. Conf., Houston, OTC8831, 1998, pp. 521529.

[19] G.J. Dyson and M.F.Randolph, "Monotonic lateral loading of piles in calcareous sand," ASCE J. Geotech. Geoenviron. Eng., pp. 346352, 2001.

[20] R.H. Al-douri and H. G. Poulos, "Static and direct shear tests on carbonate sands," Geotech. Test J., Vol. 15, No. 2, pp. 138-155, 1992.

[21] R.H. Al-douri and H.G. Poulos, "Predicted and observerd cyclic performance of piles in calcareous sand," J. Geotech. Eng., vol. 121, No.1, pp. 1-16, 1995.

[22] P.G. Waston and M.F. Randolph, "Vertical capacity of caisson foundations in calcareous sediments," In: Proc. $7^{\text {th }}$ Int. Offshore Polar Eng. Conf., Honolulu, USA, 1997, pp. 784-790.

[23] M.J. Cassidy, B.W. Byrne and G.T. Houlsby "Modeling the behaviour of circular footings under combined loading on loose carbonate sand," Geotechnique, vol. 52, No. 10, pp. 705-712, 2002.

[24] M.J.Cassidy, D.W. Airey and J.P. Carter, "Numerical modeling of circular footings subjected to monotonic inclined loading on uncemented and cemented calcareous sands," ASCE J. Geotech, Geoenviron. Eng., vol. 131, No.1, pp. 52-63, 2005.

[25] X.F. Chu, Z.G. Li, and R. Wang, "The test research of anchor's uplift behavior in calcareous sand," Rock Soil Mech. vol. 23, no. 3, pp. 368-371, 2002.

[26] H.G. Shan and R.Wang "Development of study on pile in calcareous sand," Rock Soil Mech., vol. 21, No.3, pp. 299-308, 2000.

(C) Wang et al.; Licensee Bentham Open.

This is an open access article licensed under the terms of the Creative Commons Attribution Non-Commercial License (http://creativecommons.org/licenses/by-nc/3.0/) which permits unrestricted, non-commercial use, distribution and reproduction in any medium, provided the work is properly cited. 